\title{
Stable water isotopologue ratios in fog and cloud droplets of liquid clouds are not size-dependent
}

\author{
J. K. Spiegel ${ }^{1}$, F. Aemisegger ${ }^{2}$, M. Scholl ${ }^{3}$, F. G. Wienhold ${ }^{2}$, J. L. Collett Jr. ${ }^{4}$, T. Lee ${ }^{4}$, D. van Pinxteren ${ }^{5}$, S. Mertes ${ }^{5}$, \\ A. Tilgner ${ }^{5}$, H. Herrmann ${ }^{5}$, R. A. Werner ${ }^{1}$, N. Buchmann ${ }^{1}$, and W. Eugster ${ }^{1}$ \\ ${ }^{1}$ Institute of Agricultural Sciences, ETH Zurich, Zurich, Switzerland \\ ${ }^{2}$ Institute for Atmospheric and Climate Science, ETH Zurich, Zurich, Switzerland \\ ${ }^{3}$ US Geological Survey, Reston, VA, USA \\ ${ }^{4}$ Department of Atmospheric Science, Colorado State University, Fort Collins, Colorado, USA \\ ${ }^{5}$ Leibniz Institute for Tropospheric Research, Leipzig, Germany
}

Correspondence to: W. Eugster (eugsterw@ethz.ch)

Received: 4 April 2012 - Published in Atmos. Chem. Phys. Discuss.: 21 May 2012

Revised: 24 September 2012 - Accepted: 2 October 2012 - Published: 29 October 2012

\begin{abstract}
In this work, we present the first observations of stable water isotopologue ratios in cloud droplets of different sizes collected simultaneously. We address the question whether the isotope ratio of droplets in a liquid cloud varies as a function of droplet size. Samples were collected from a ground intercepted cloud (= fog) during the Hill Cap Cloud Thuringia 2010 campaign (HCCT-2010) using a three-stage Caltech Active Strand Cloud water Collector (CASCC). An instrument test revealed that no artificial isotopic fractionation occurs during sample collection with the CASCC. Furthermore, we could experimentally confirm the hypothesis that the $\delta$ values of cloud droplets of the relevant droplet sizes ( $\mu$ m-range) were not significantly different and thus can be assumed to be in isotopic equilibrium immediately with the surrounding water vapor. However, during the dissolution period of the cloud, when the supersaturation inside the cloud decreased and the cloud began to clear, differences in isotope ratios of the different droplet sizes tended to be larger. This is likely to result from the cloud's heterogeneity, implying that larger and smaller cloud droplets have been collected at different moments in time, delivering isotope ratios from different collection times.
\end{abstract}

\section{Introduction}

In order to use stable water isotopologues $\left({ }^{1} \mathrm{H}_{2}{ }^{16} \mathrm{O}\right.$, ${ }^{1} \mathrm{H}^{2} \mathrm{H}^{16} \mathrm{O}$, and ${ }^{1} \mathrm{H}_{2}{ }^{18} \mathrm{O}$ ) as a tool to assess paleoclimatical (e.g. Dansgaard et al., 1993; Petit et al., 1999), ecological (e.g. Yakir and Sternberg, 2000; Farquhar et al., 2007) and hydrological questions (e.g. Dansgaard, 1964), a quantitative understanding of processes involving stable water isotopologues in the hydrosphere is needed. Important mechanisms herein are cloud and precipitation formation (Jouzel, 1986). Cloud modeling is one way to gain insights into these processes (Jouzel, 1986). In recent years, modeling efforts focused on the explanation of observed trends of isotope ratios in precipitation, both on a local and a global scale (Lee and Fung, 2007; Risi et al., 2008), aiming for a better understanding of the "amount effect". This effect describes the on-going depletion of precipitation water in heavy isotopologues with increasing rain intensity.

An important assumption used in cloud models is that the cloud droplets are in isotopic equilibrium with the surrounding water vapor, leading to cloud droplets which do not differ in isotope ratios for different droplet sizes (Jouzel, 1986). This assumption was first presented by Bolin (1958) who carried out a theoretical analysis of tritium isotope exchange between single freely falling rain droplets and their environment, based on the laboratory work by Kinzer and Gunn (1951). Additionally, laboratory studies of the isotopic exchange rate of single falling droplets (Friedman et al., 1962; Booker, 1964; Stewart, 1975) further strengthened Bolin's work. Based on a theoretical framework, Jouzel et al. (1975) demonstrated that a cloud droplet with radius less than $30 \mu \mathrm{m}$ could be considered to be in isotopic equilibrium with water 
vapor independent of the cloud conditions. However, to our knowledge, no measurements in clouds or fog have been carried out so far to confirm that the results from single falling droplets can be applied to an ensemble of cloud droplets with multiple and more complex interactions, and that droplets do not differ in isotope ratio for different sizes. Due to different inertia, droplets of different sizes are affected differently by cloud dynamics: larger droplets settle faster, while smaller droplets might be transported higher in the cloud (Gedzelman and Arnold, 1994). Thus, different droplet sizes could carry isotopic information from different locations in the cloud. Moreover, as the equilibrium vapor pressure increases with increasing curvatures, larger droplets slowly grow at the expense of smaller ones and might therefore have longer life times, which could additionally influence the isotope ratio of the droplets.

In this study, we present the first experimental evidence that there is no difference in isotope ratios for different droplet sizes in hill cap clouds dominated by liquid phase microphysics. The $\delta$ values of the cloud droplets of three different relevant size classes did not differ significantly.

\section{Materials and methods}

\subsection{Measurement site and HCCT-2010 field experiment}

Cloud data were gathered during the Hill Cap Cloud Thuringia 2010 (HCCT-2010) field campaign, which took place close to the summit of Schmücke $\left(50^{\circ} 39^{\prime} 19^{\prime \prime} \mathrm{N}\right.$, $10^{\circ} 46^{\prime} 15^{\prime \prime}$ E, $937 \mathrm{~m}$ a.s.1., Germany) in September and October 2010. In total, cloud samples from 13 different nonprecipitating cloud events with temperatures $>0{ }^{\circ} \mathrm{C}$ (presented in more detail in Spiegel et al., 2012) were collected using a three-stage Caltech Active Strand Cloud water Collector (CASCC, Sect. 2.2).

The events lasted between 3 and $15 \mathrm{~h}$, mostly at night time, resulting in 1 to 8 cloud samples per event, depending on the collection time per sample ( 1 to $3 \mathrm{~h}$ ). More detailed information can be found in the raw data set (http://doi.pangaea.de/ 10.1594/PANGAEA.788631). Each cloud sample consisted of the three vials from the three stages of the CASCC. For the discussion of the temporal evolution of the isotope ratio during the cloud events as well as for details and the general interpretation we refer to Spiegel et al. (2012), and hence use the same numbering as in Spiegel et al. (2012).

From a meteorological point of view the cloud that was probed at Schmücke should be called fog - as fog is a cloud that touches the ground (Pruppacher and Klett, 1997). However, from a process based point of view, the microphysical processes within the cloud do not change at the moment when an advected cloud touches the ground. We therefore use the terms fog and cloud interchangeably throughout this work. In addition to the collection of cloud water samples, other cloud properties were monitored as well in the frame-

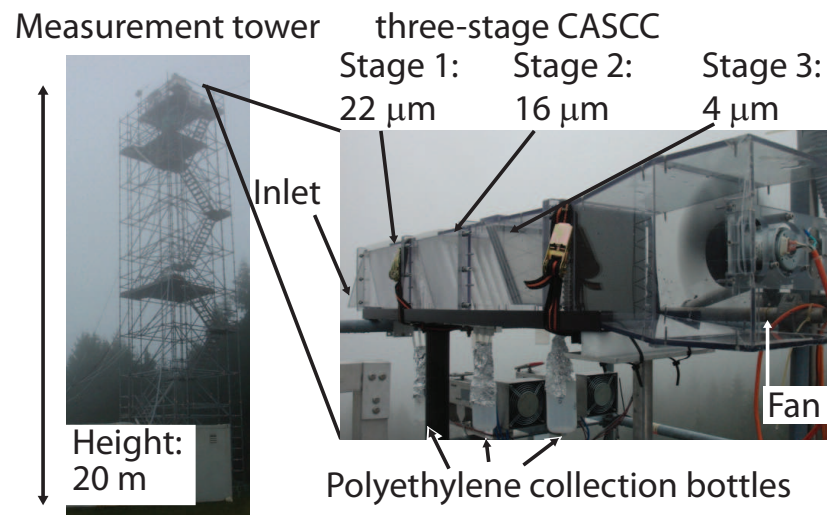

Fig. 1. Pictures of the measurement tower at Schmücke $\left(50^{\circ} 39^{\prime} 19^{\prime \prime} \mathrm{N}, 10^{\circ} 46^{\prime} 15^{\prime \prime} \mathrm{E}, 937 \mathrm{~m}\right.$ a.s.1, Germany) and of the threestage Caltech Active Strand Cloudwater Collector (CASCC, as described in Sect. 2.2) mounted on its top. The figure includes the $50 \%$ cut-off sizes for cloud droplet diameters collected at the different stages: stage 1 collects droplets larger than $\approx 22 \mu \mathrm{m}$, stage 2 droplets from 16 to $22 \mu \mathrm{m}$ and stage 3 from 16 to $4 \mu \mathrm{m}$.

work of the HCCT-2010 campaign. In this work, we use the liquid water content (LWC) and the effective radius $\left(R_{\mathrm{eff}}\right)$ as measures for the microphysical state of the cloud. LWC is the sum of the volumes of cloud droplets per unit air volume, and $R_{\text {eff }}$ is defined as the radius yielding the same volume to surface ratio as the ambient cloud droplet size distribution. LWC and $R_{\text {eff }}$ were measured with a Particulate Volume Monitor (PVM-100, Gerber Scientific, USA) which determines the LWC via light scattering by the present droplets (Gerber, 1991; Arends et al., 1994). As the total surface of the droplets is also measured by the PVM-100, the $R_{\text {eff }}$ (which is the LWC divided by the total surface of the cloud droplets) can be retrieved.

\subsection{Collection of cloud water samples}

In order to obtain size resolved cloud water samples a threestage CASCC was used, mounted on a tower $20 \mathrm{~m}$ above ground (see Fig. 1). The three-stage CASCC is a modified version of the size-fractionating CASCC designed for the collection of cloud droplets in two size fractions (Demoz et al., 1996). The working principle is as follows. Cloud droplets are drawn by a fan through a duct, and are collected by means of impaction. For increasing particle size their inertia decreases the ability to follow the gas stream line. By introducing obstacles into the flow, droplets of a certain size - corresponding to the obstacle morphology - can be inertially collected from the air flow (Demoz et al., 1996). In the three-stage CASCC, stages one to three consist of banks of Teflon rods of three different sizes which are used as impaction obstacles. The rods are inclined, allowing the collected fog water to flow into a Teflon sample trough (one per stage) then through a Teflon tube into a closed polyethylene 
collection bottle (one per stage). The larger the diameter of the rods, the larger the collected droplets are at the particular stage.

We ran the CASCC with a volume flow of $19 \mathrm{~m}^{3} \mathrm{~min}^{-1}$. Based on modeling results presented by Raja et al. (2008), the expected $50 \%$ size cuts for stage one, two and three were approximately 22,16 and $4 \mu \mathrm{m}$, respectively. The term $50 \%$ size cut corresponds to the droplet size at which droplets are collected with a $50 \%$ efficiency; larger droplets are collected with a higher and smaller droplets with a smaller efficiency. Consequently, droplets collected on adjacent stages overlap in size and thus measured composition differences are conservative estimates of actual differences in composition versus droplet size. The size of the largest droplets capable of entering the CASCC and being collected in the first stage depends on the ambient wind conditions and is estimated to be in the range of $100 \mu \mathrm{m}$, well above the volume mode of typical cloud droplet size distributions. When rain was expected, we deployed the collector with a downward facing inlet to inhibit raindrops entering the CASCC.

Sampling times varied between 1 to $3 \mathrm{~h}$ per cloud sample depending on the cloud conditions. Then the polyethylene bottles were detached from the sampler and the cloud water for isotope ratio analysis was immediately filled into glass vials $(1.5 \mathrm{ml})$ that were closed to inhibit additional evaporation which might change the isotope ratio. Additionally, during the campaign, six test samples for isotopic fractionation were collected (later on referred to as DI-samples), by spraying deionized water (DI; with known $\delta$ value) into the cleaned sampler using a commercially available spraying bottle. The procedure lasted around $30 \mathrm{~min}$ until each of the sampling bottles was filled with approximately $250 \mathrm{ml}$. To ensure saturated conditions inside the CASCC during the collection of these samples, the fan was turned off. Different CASCC versions have frequently been used for the collection of cloud water for chemical analysis (e.g. Moore et al., 2004a,b; Collett Jr. et al., 2008; Kaul et al., 2011). One-stage CASCCs have already been used for isotope ratio analysis (Schmid et al., 2010) and MiniCASCCs have been recommended as an appropriate tool for sample collection for isotope ratio analysis (Michna et al., 2007; Scholl et al., 2011). As cloudy air is slightly supersaturated, we expect equilibrium isotopic fractionation to dominate. The saturated conditions persist within the CASCC and we therefore assume that no additional isotopic fractionation occurs during sampling. Consequently, the cloud water within the collection bottle represents the average $\delta$ value of cloud droplets for the collection time of each stage.

\subsection{Stable water isotopologue analyses}

Each cloud sample consisted of three vials each from one stage of the CASCC. The cloud water was analysed for $\delta^{2} \mathrm{H}$ and $\delta^{18} \mathrm{O}$ values using the high-temperature carbon reduction method by coupling a high-temperature elemental analyser
(TC/EA; Finnigan MAT, Bremen, Germany) to a Delta ${ }^{\text {plus }} \mathrm{XP}$ isotope ratio mass spectrometer (IRMS) via a ConFlo III interface (both Finnigan MAT). The measurement set-up of the carbon reduction tube followed the "MPI-BGC method" (see Gehre et al., 2004, for details). Hydrogen and oxygen ratios $R_{\text {sample }}\left({ }^{2} \mathrm{H} /{ }^{1} \mathrm{H}\right.$ and $\left.{ }^{18} \mathrm{O} /{ }^{16} \mathrm{O}\right)$ were expressed as $10^{3} \times \delta^{2} \mathrm{H}$ and $10^{3} \times \delta^{18} \mathrm{O}$ (in this text we use the \%o sign behind the numbers in order to improve readability) in relation to the Vienna Standard Mean Ocean Water $\left(R_{\mathrm{V}-\mathrm{SMOW}}\right)$ normalized such that the SLAP (= Standard Light Antarctic Precipitation) reference water was $-55.5 \%$ for $\delta^{18} \mathrm{O}$ and $-428 \%$ o for $\delta^{2} \mathrm{H}$ (Coplen, 1988, 2011):

$\delta=\frac{R_{\text {sample }}}{R_{\mathrm{V}-\mathrm{SMOW}}}-1$.

The precision of this measurement was assessed by measuring a quality control lab standard water (WP-0503-Z0010B, once in an analytical measurement sequence which comprises 60 samples), resulting in an uncertainty of $0.3 \delta$ units and $0.04 \delta$ units (peak-jump) over all measurements for $\delta^{2} \mathrm{H}$ and $\delta^{18} \mathrm{O}$, respectively. Each vial was measured three times. Reported $\delta$ values are the mean values of these three measurements including standard error.

\subsection{Isotopic equilibration time of a motionless droplet}

In this section, we present the simplified model for a motionless droplet in order to deduce a theoretical estimate for the isotopic equilibration time of a cloud droplet. In contrast to earlier studies treating mostly larger rain droplets (e.g. Friedman et al., 1962; Jouzel, 1986; Lee and Fung, 2007), we chose the model of the motionless droplet, as settling velocities of cloud droplets are small (from $3.5 \times 10^{-5} \mathrm{~m} \mathrm{~s}^{-1}$ to $0.07 \mathrm{~m} \mathrm{~s}^{-1}$ for droplets of 1 to $50 \mu \mathrm{m}$ in diameter according to Seinfeld and Pandis (2006)) and thus ventilation effects that affect the mass transfer can be ignored. Due to the high diffusion coefficients within water, individual rain and cloud droplets can be considered to be isotopically homogeneous (Jouzel, 1986). Cloud droplets grow and shrink via the exchange of mass with the surrounding (saturated) vapor by diffusion in air. Considering a motionless cloud droplet the rate of change of droplet mass is given by Pruppacher and Klett (1997):

$\frac{\partial m_{i}}{\partial t}=4 \pi r D_{i}\left(\rho_{i, r}-\rho_{i, \infty}\right)$,

where $m_{i}$ is the mass of the isotopologue in a cloud droplet with radius $r$ and with $i$ standing either for ${ }^{1} \mathrm{H}_{2}{ }^{16} \mathrm{O}$, ${ }^{1} \mathrm{H}^{2} \mathrm{H}^{16} \mathrm{O}$, and ${ }^{1} \mathrm{H}_{2}{ }^{18} \mathrm{O}$, respectively. $D_{i}$ are the diffusivities for the different isotopologues (for this study we took diffusivity values from Cappa et al., 2003), and $\rho_{i, r}$ and $\rho_{i, \infty}$ are the vapor densities of the isotopologues $i$ at the droplet surface $(r)$ and the surrounding air $(\infty)$, respectively. Equation (2) is valid for droplets larger than the mean free path $\lambda$ of air molecules which is $0.0651 \mu \mathrm{m}$ at $1 \mathrm{~atm}$ and $298 \mathrm{~K}$ 
according to Seinfeld and Pandis (2006). Non-continuum effects of very small cloud droplets are not considered, as the contribution of these cloud droplets to the collected cloud water is small due to their small volume. The equilibrium isotopic fractionation coefficient $\alpha_{k}$ (here we use equations presented by Criss (1999), to calculate $\alpha_{k}$, with $k^{1} \mathrm{H}^{2} \mathrm{H}^{16} \mathrm{O}$, and ${ }^{1} \mathrm{H}_{2}{ }^{18} \mathrm{O}$ ) for the phase change from liquid to vapor is defined as:

$\alpha_{k}=\frac{R_{c, k}}{R_{v, k}}=\frac{\frac{m_{k}}{m_{16}}}{\frac{\rho_{k}}{\rho_{16}}}$,

with $R_{c, k}$ denoting the corresponding isotope ratio in the condensed phase and $R_{v, k}$ being the isotope ratio in the vapor phase for the isotopologue $k$. Using Eq. (3), the ideal gas equation $\left(\rho_{16}=\frac{e_{w}}{R_{v w} T}\right)$, and $m_{16}=4 / 3 r^{3} \pi$, the solution for Eq. (2) is:

$m_{\mathrm{eq}, k}-m_{k}(t)=\left(m_{\mathrm{eq}, k}-m_{k}(0)\right) \exp \left(-t / \tau_{k}\right)$.

where $m_{k}(t)$ and $m_{k}(0)$ are the mass of isotopologue $k$ in the droplet at the time $t$ and $t=0$, respectively, and $m_{\mathrm{eq}, k}$ is the mass of isotopologue $k$ in the droplet when the droplet is in isotopic equilibrium with the surrounding vapor. $\tau_{k}$ is the $e$-folding time, which is the time interval in which $m_{\mathrm{eq}, k}-$ $m_{k}(t)$ decreased by a factor $e$ in comparison to the initial difference $m_{\mathrm{eq}, k}-m_{k}(0)$ :

$\tau_{k}=\frac{\alpha_{k} r^{2} \rho_{l} R_{w v} T}{3 D_{k} e_{w}}$,

where $R_{w v}=461.5 \mathrm{~J} \mathrm{~kg}^{-1} \mathrm{~K}^{-1}$ is the gas constant for water vapor and $e_{w}$ is the saturation vapor pressure of water vapor at temperature $T$ in (K). Using the $e$-folding time $\tau_{k}$ (Eq. 5), the time required to reach $99 \%\left(t_{99}=4.5 \times \tau_{k}\right)$ of isotopic equilibrium with the surrounding air is reported in the subsequent section.

\section{Results and discussion}

\subsection{Equilibration times for droplet sizes in fog and liquid clouds}

For temperature and air pressure conditions found during HCCT-2010, the isotopic equilibration time $t_{99}$ is less than $30 \mathrm{~s}$ for all relevant droplet sizes in fog and smallest for the smallest droplet diameters that were sampled (Fig. 2). The calculated value of $t_{99}$ decreased slightly with increasing temperature and was smaller for ${ }^{1} \mathrm{H}_{2}{ }^{18} \mathrm{O}$ than for ${ }^{1} \mathrm{H}^{2} \mathrm{H}^{16} \mathrm{O}$ (as $\alpha_{1} \mathrm{H}^{2} \mathrm{H}^{16} \mathrm{O}>\alpha_{1} \mathrm{H}_{2}{ }^{18} \mathrm{O}$ for this temperature range and $\left.D_{1} \mathrm{H}^{2} \mathrm{H}^{16} \mathrm{O}>D_{1_{\mathrm{H}_{2}}{ }^{18} \mathrm{O}}\right)$. However, these $t_{99}$ values were calculated for a single motionless droplet. Extending the analysis from one single droplet to an ensemble of droplets has been discussed by Jouzel et al. (1975) who came to the conclusion that this step would reduce the equilibration time,

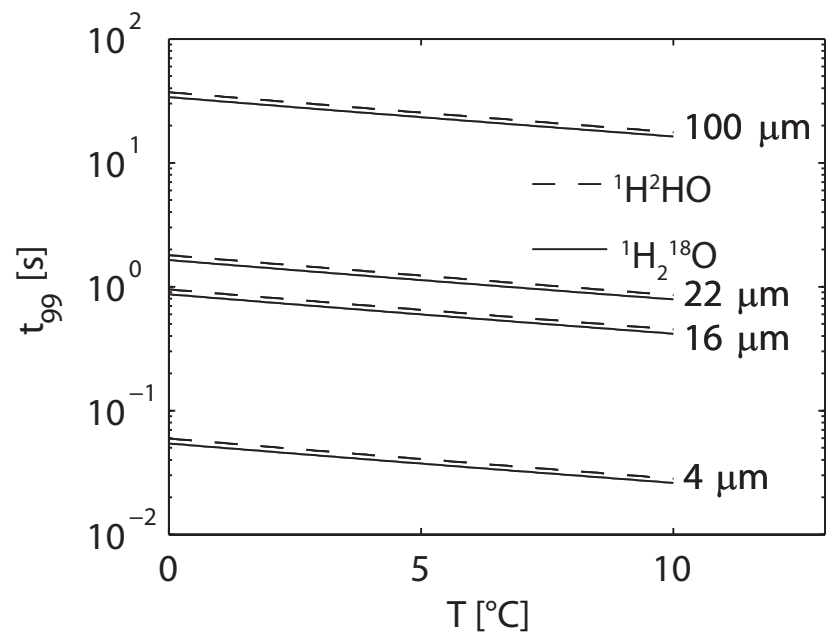

Fig. 2. Time required for a single spherical cloud droplet to reach $99 \%$ isotopic equilibrium (both for $\delta^{2} \mathrm{H}$ and $\delta^{18} \mathrm{O}$ ) with the surrounding vapor at air temperatures prevailing at Schmücke. $t_{99}$ is depicted for four different droplet diameters: $22 \mu \mathrm{m}, 16 \mu \mathrm{m}$ and $4 \mu \mathrm{m}$ corresponding to the cut-off sizes of the three stages of the CASCC, and $100 \mu \mathrm{m}$ which we assume to be the diameter of the largest droplets that enter the CASCC. $D_{k}$ values $\left(k={ }^{1} \mathrm{H}^{2} \mathrm{H}^{16} \mathrm{O}\right.$, and ${ }^{1} \mathrm{H}_{2}{ }^{18} \mathrm{O}$ ) were deduced from the relations to $D^{{ }_{1}} \mathrm{H}_{2}{ }^{16} \mathrm{O}$ (Cappa et al., 2003), and $D^{{ }^{1}} \mathrm{H}_{2}{ }^{16} \mathrm{O}$ was derived from campaign temperature and the air pressure value $(900 \mathrm{hPa})$ using the relation presented by Hall and Pruppacher (1976).

as the droplets also grow due to collision and coalescence. In summary, this implies that cloud droplets are in principle almost instantaneously in isotopic equilibrium with the surrounding water vapor. Consequently, droplets basically immediately "forget" their isotopic information which they carry arriving from a different location in the cloud or as a result from longer droplet live times. Based on such short equilibration times, we do not expect that differences in $\delta$ values among droplet sizes can be measured with the conventional CASCC sampling technique, as the sampling intervals of 1 to $3 \mathrm{~h}$ were much larger than the equilibration times.

\subsection{Collector performance}

To verify the collector performance of the CASCC six DI-samples have been collected and analyzed for isotope ratio (raw data available on http://doi.pangaea.de/10.1594/ PANGAEA.788628). A two-way ANOVA with the factors sample number (corresponds to the factor Time in Table 1) and size stages (Size, Table 1) revealed that there was no significant difference in $\delta$ values between the deionized water $\left(\delta^{2} \mathrm{H}_{\mathrm{DI}}=-63.2 \pm 0.8 \%\right.$ and $\left.\delta^{18} \mathrm{O}_{\mathrm{DI}}=-9.63 \pm 0.05 \% o\right)$ and the DI-samples, independent of the ambient meteorological conditions. This agrees with the findings from Sect. 3.1 and the assumptions made in Sect. 2.2: As the fan was turned off, the exchange of water vapor between the saturated water vapor volume inside the CASCC (which resulted from 
Table 1. $F$ - and $p$-values for a two way ANOVA (factors: Time and Size) for the measured $\delta^{2} \mathrm{H}$ and $\delta^{18} \mathrm{O}$ values for the six DI-samples and for each cloud event separately comprising more than one cloud sample. The factor Time is represented by the sample number within an event and was used as a categorical variable in the ANOVA. Bold indicates that the null hypothesis needs to be rejected at a significance level $\alpha=0.05$ ( $\mathrm{H}_{0}$ (events): Cloud water from all vials have the same $\delta$ values; $\mathrm{H}_{0}$ (DI-samples): Water from all vials have the same $\delta$ values as the DI water). For events $1,5,7$ and 12, the ANOVA was only performed for $\delta$ values from stage 1 and 3 , as at least one $\delta$ value for the stage 2 was missing. As there were 18 independent tests necessary for the cloud events, we applied the Bonferroni correction (Legendre and Legendre, 1998) resulting in an adjusted significant level $\alpha_{\text {adj }}=0.05 / 18=2.7 \times 10^{-3}$ against which the $p$-values were compared.

\begin{tabular}{|c|c|c|c|c|c|c|c|c|}
\hline \multirow[b]{3}{*}{ Event } & \multicolumn{4}{|c|}{$\delta^{2} \mathrm{H}$} & \multicolumn{4}{|c|}{$\delta^{18} \mathrm{O}$} \\
\hline & \multicolumn{2}{|c|}{ Size } & \multicolumn{2}{|c|}{ Time } & \multicolumn{2}{|c|}{ Size } & \multicolumn{2}{|c|}{ Time } \\
\hline & $F$-value & $p$-value & $F$-value & $p$-value & $F$-value & $p$-value & F-value & $p$-value \\
\hline DI-samples & 0.5 & 0.6297 & 1.6 & 0.2508 & 0.1 & 0.9047 & 2.4 & 0.1158 \\
\hline 1 & 0.7 & 0.4255 & 67.1 & $<\mathbf{1 0}^{-5}$ & 7.1 & 0.0373 & 81.0 & $<10^{-5}$ \\
\hline 3 & 9.0 & 0.1001 & 161.4 & 0.0061 & 2.6 & 0.2792 & 68.3 & 0.0143 \\
\hline 5 & 4.5 & 0.2802 & 0.7 & 0.5677 & 33.4 & 0.1091 & 2.9 & 0.3403 \\
\hline 6 & 0.1 & 0.8980 & 3.7 & 0.0811 & 2.4 & 0.1739 & 11.9 & 0.0062 \\
\hline 7 & 3.8 & 0.1914 & 1360.6 & 0.0007 & 98.3 & 0.0100 & 25205.0 & $<\mathbf{1 0}^{-5}$ \\
\hline 9 & 0.8 & 0.4943 & 197.5 & $<\mathbf{1 0}^{-5}$ & 0.8 & 0.4703 & 69.0 & $<10^{-5}$ \\
\hline 10 & 4.4 & 0.0338 & 81.07 & $<\mathbf{1 0}^{-5}$ & 1.0 & 0.3817 & 13.3 & $<10^{-5}$ \\
\hline 11 & 0.1 & 0.8782 & 15.0 & 0.0139 & 0.2 & 0.8536 & 6.5 & 0.0550 \\
\hline 12 & 0.6 & 0.52 & 478.76 & 0.0021 & 2.3 & 0.2721 & 1348.2 & 0.0007 \\
\hline
\end{tabular}

continuously spraying deionized water into the CASCC) and the non-saturated conditions outside the CASCC was small. Therefore, the isotope ratio of both water vapor and droplets in the CASCC was mainly determined by the isotope ratio of the deionized water. As the collected water in the collection bottles did not differ significantly in isotope ratio from the deionized water used for spraying, we conclude that no isotopic fractionation occurs during sampling. Hence, the collected cloud water samples are representative of the actual isotope ratio of the cloud droplets.

\subsection{Hydrogen and oxygen isotope ratios of cloud water}

In events 1, 5, 7, 8 and 12, cloud water could not be analyzed for all stages, as either the vials broke (event 7) or insufficient cloud water had been collected (events 1, 5, 7 and 12). So in total, 115 vials could be used for the following analysis.

$\delta$ values varied over the whole measurement campaign from $-77 \%$ o to $-15 \% \circ\left(\delta^{2} \mathrm{H}\right)$ and from $-12.1 \%$ to $-3.9 \%$ o $\left(\delta^{18} \mathrm{O}\right.$; Fig. 3) and were slightly more depleted in heavy isotopologues than the $\delta$ values that have been measured in fog in earlier studies (tabulated in Scholl et al., 2011, from $-71 \%$ o to $+13 \%$ o for $\delta^{2} \mathrm{H}$ and $-10.4 \%$ o to $+2.7 \%$ for $\delta^{18} \mathrm{O}$ ). Nevertheless, the spread of our data was comparable to what has been measured before.

The variability in $\delta$ values over time was generally larger than the differences between the different size fractions from the fog collector (Fig. 3). Additionally, there was no clear tendency of cloud water from one size fraction being more enriched in heavy isotopologues than cloud water from the others. In order to quantitatively determine whether there was a difference between the isotope ratio for the different droplet sizes, we carried out a two-way ANOVA for each event separately, comprising at least two samples (Table 1). As the focus of the ANOVA was on the differences between droplet sizes, we chose both the Time within the event (Table 1) and the collector stage (size in Table 1) as factors. Time was treated as a categorical variable represented by the sample number in our ANOVA. This means that we only tested whether time in the event has an effect on the overall variance in our data, neglecting the question whether the absolute time interval between samplings also has an effect. To account for the increasing probability of type I error (rejecting the null hypothesis although it is true) due to 18 independent ANOVAs, we adjusted the significance level $\alpha=0.05$ using the Bonferroni criterion: $\alpha_{\text {adj }}=0.05 / 18=2.7 \times 10^{-3}$ (Legendre and Legendre, 1998). The vials taken from the different stages of the collector did not differ significantly (significance level $p<\alpha_{\text {adj }}$ ) in their $\delta^{2} \mathrm{H}$ and $\delta^{18} \mathrm{O}$ values. As the Bonferroni criterion often leads to a very small $\alpha_{\text {adj }}$, we also used Holm's procedure (Holm, 1979) to account for multiple testing, which did not change the results.

Hence, these data are the first stable water isotopologue data for size resolved cloud droplet sampling, providing empirical evidence that there is no difference in isotope ratios for different cloud droplet sizes of the same cloud measured at the same time. This finding is in agreement with what we would expect from the equilibration times calculated for a single droplet illustrating that this simple model can be applied to a droplet ensemble. Still, for most of the events, the samples differed significantly with respect to elapsed time. 


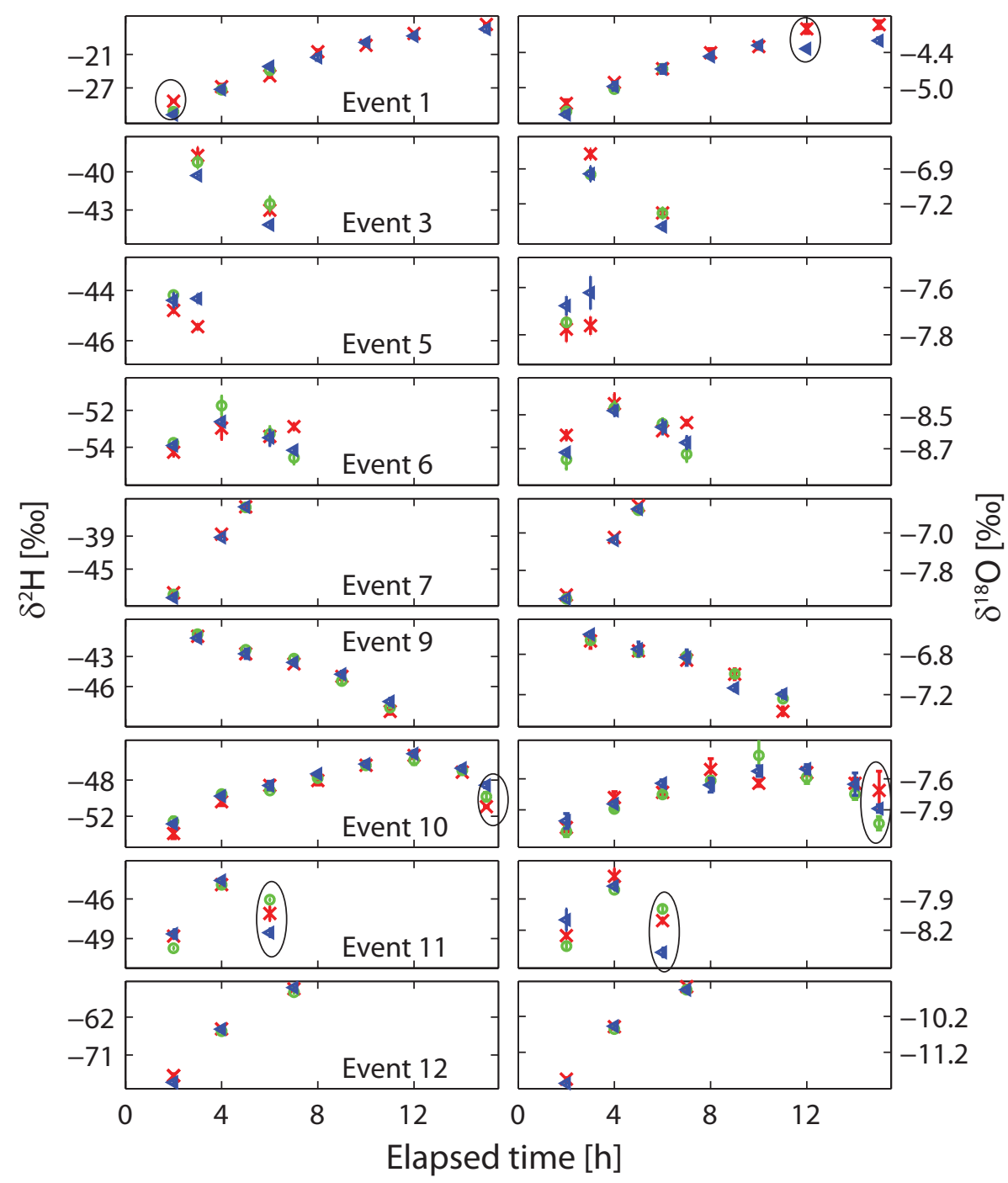

\begin{tabular}{|c|c|c|c|c|c|}
\hline$x$ & stage $1(22 \mu \mathrm{m})$ & o & stage $2(16 \mu \mathrm{m})$ & 4 & stage $3(4 \mu \mathrm{m})$ \\
\hline
\end{tabular}

Fig. 3. Temporal evolution of the $\delta^{2} \mathrm{H}$ and $\delta^{18} \mathrm{O}$ values for all measured cloud events during HCCT lasting longer than one measurement point: $\delta$ values for the different stages are shown in different colors and different symbols and denoted with their cut-off diameters in brackets. Measurement error in terms of standard errors of the IRMS measurements are shown as error bars. Cloud samples exceeding the $\Delta_{\text {st }} 90-$ percentile threshold (see Fig. 4 for further details) are marked with an ellipse. Identification of the drivers of this temporal evolution as well as interpretation is presented in Spiegel et al. (2012).

Besides changes in local thermodynamic conditions, airmass history and transport as well as frontal passages could be identified as reasons for these temporal changes in $\delta$ values in the cloud droplets which are discussed in detail in Spiegel et al. (2012).

\subsection{Cloud dissolution}

Although the two-step ANOVA showed that the differences among the stages were not significant, the maximal differences among the stages $\left(\Delta_{\text {st }}=\max _{i, j=1,2,3}\left(\left|\delta_{i}-\delta_{j}\right|\right)\right)$ tended to be larger for the first and the last data points during the course of the event as well as for certain single sample events (Fig. 3).

This is discussed by a more detailed investigation of the cloud sampling intervals in which $\Delta_{\mathrm{s} t}$ was above the 90 percentile both for $\delta^{2} \mathrm{H}$ and $\delta^{18} \mathrm{O}$. This was the case for the last cloud samples of event 10 and 11 (Figs. 3 and 4) as well as the sample of event $4^{1}$. We selected event 11 as a model

\footnotetext{
${ }^{1}$ Only one cloud sample was collected during event 4 with the following $\delta$ values including standard errors for stage 1 , 2, and 3: $-72 \pm 0.3 \% o,-74 \pm 0.3 \%$, and $-72 \pm 0.2\left(\delta^{2} \mathrm{H}\right)$ and $-10.9 \pm 0.02 \%$ o, $-11.4 \pm 0.03 \%$ and $-11.0 \pm 0.10 \%$ o $\left(\delta^{18} \mathrm{O}\right)$.
} 


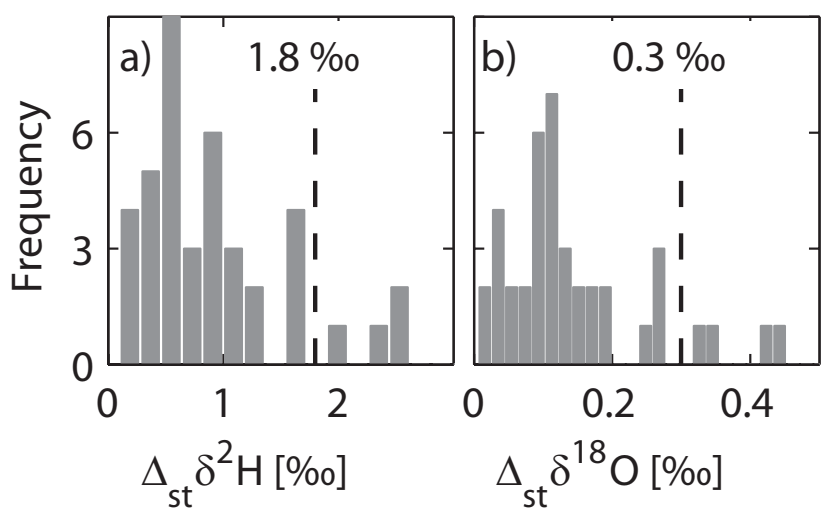

Fig. 4. Histograms for the maximum differences in $\delta^{2} \mathrm{H}$ (a) and $\delta^{18} \mathrm{O}(\mathbf{b})$ values among vials of the three stages collected by the $\operatorname{CASCC}\left(\Delta_{\mathrm{st}}=\max _{i, j=1,2,3}\left(\left|\delta_{i}-\delta_{j}\right|\right)\right)$ for all cloud samples. The dashed line denotes the 90 -percentile of the $\Delta_{\text {st }}$ distribution $(1.8 \%$ o or $0.3 \%$ ).

event to explain the process leading to larger differences between $\delta$ values of different stages at the end of a cloud event (see Fig. 5): The last cloud sample was collected during the dissolution period of the cloud (gray hatched area in Fig. 5c) which was characterized by a decreasing LWC during the sampling interval (gray line in Fig. 5c). As LWC remained $>0 \mathrm{~g} \mathrm{~m}^{-3}$, we assume that the air was still supersaturated with water vapor during sampling. Simultaneously, the ef-

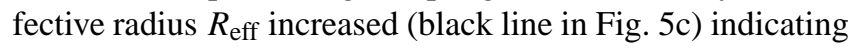
that the smaller droplets evaporate first when supersaturation decreases. Consequently, the cloud water of stage 3 was probably collected at the beginning of the sampling interval, while the other two stages continued collecting cloud water until the end of the sampling interval when smaller droplets had already disappeared (Fig. 5d). If we now assume that the $\delta^{2} \mathrm{H}$ changed during the sampling interval (hypothetical $\delta^{2} \mathrm{H}$ of cloud droplets in Fig. 5d), stage three represents a $\delta$ value from the beginning of the sampling interval, while the $\delta$ value of the cloud water collected in stage one and two is a mean value of the whole sampling interval, which could explain the observed difference. On the other hand, during sampling interval 2, LWC and $R_{\text {eff }}$ stay rather constant (Fig. 5c), indicating that all stages collected cloud water continuously. So in all three stages, the measured $\delta$ value represents a mean value over the whole sampling interval 2 leading to a much smaller difference between the stages than during sampling interval 3 (Fig. 5a). For the last cloud sample of event 10, LWC and $R_{\text {eff }}$ behaved similarly as described for event 11 , indicating cloud dissolution and hence the same collection artifact. During cloud event $4, R_{\text {eff }}$ varied strongly during the whole sampling interval. Hence, we assume a rather inhomogeneous cloud and it is likely that the cloud water was not collected simultaneously in the different stages for these cloud samples as well, as not all droplet sizes were present during the whole sampling interval. Consequently, we as- a)

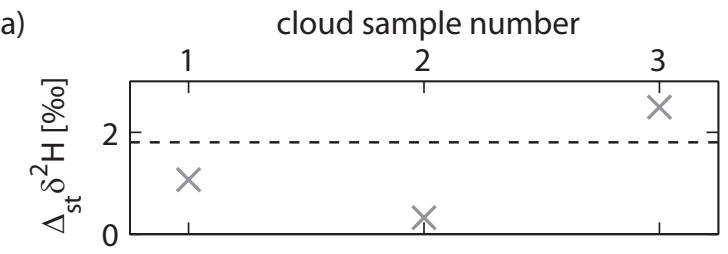

b)

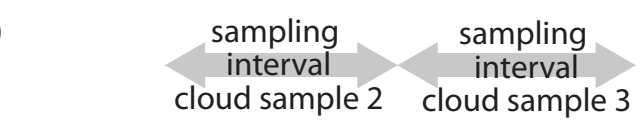

c)
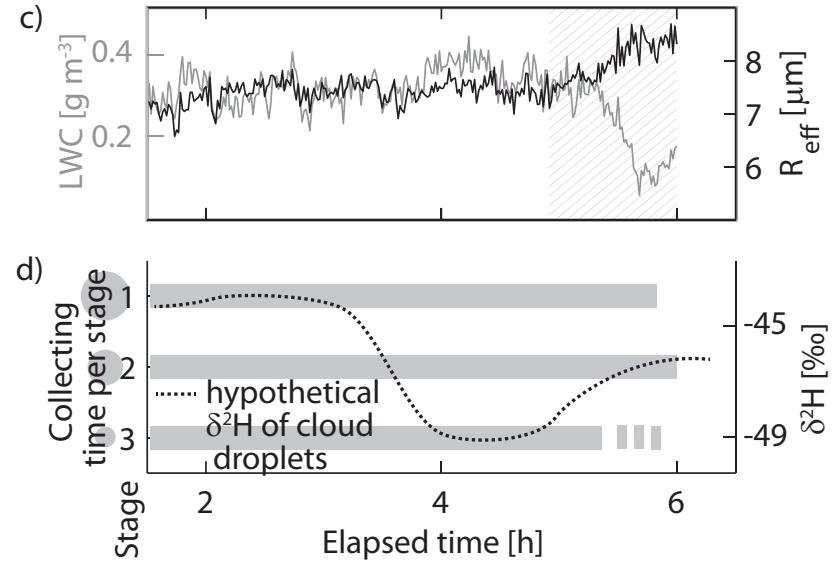

Fig. 5. Illustration of the collection artifact arising during the dissolution period of the cloud for event 11. (a) $\Delta_{\mathrm{s} t} \delta^{2} \mathrm{H}$ for all cloud samples of event 11 including the $1.8 \%$ o threshold as a dashed line. (b) Sampling intervals of cloud sample 2 and 3 (1 is not shown). (c) Liquid water content (LWC) and effective radius $\left(R_{\text {eff }}\right)$ measured with the Particulate Volume Monitor (PVM-100). The dissolution period of the cloud is indicated as a hatched area. (d, left axis) Collecting times (estimated from the measurements in panel (c)) for the three different CASCC stages and (d, right axis) hypothetical $\delta^{2} \mathrm{H}$ evolution in cloud droplets which could lead to the observed $\Delta_{\mathrm{s} t} \delta^{2} \mathrm{H}$ depicted in (a). See Sect. 3.4 for detailed explanation.

sume that the differences in isotope ratios among the stages for these cloud samples should be considered the result of different collection times for the different size stages, which can be regarded as a collection artifact.

\section{Conclusions}

In this work, we present the first size-resolved measurements of stable water isotopologue ratios in cloud droplets. Our result confirms our expectation that differences in isotope ratios measured simultaneously in three size fractions are within the analytical precision of the IRMS (Table 1). This result is independent of the isotope ratio itself and valid for the whole range of $\delta$ values of the collected samples. Our equipment analysis also verified that there is no isotopic fractionation of samples collected in a large-size active-strand cloud collector (CASCC). Based on our measurements and the theory presented we therefore expect no difference in $\delta$ 
values of all droplet sizes in fog. However, when the cloud dissipated the differences between droplet sizes tended to be larger, most probably reflecting different collection times of the respective droplet sizes. Our suggestions for future studies are (1) that non-size resolved sampling of cloud droplets is adequate and representative to measure the isotope ratio of cloud droplets of all sizes, and (2) as the isotope ratio of cloud water evolves with time, it is desirable to test shorter sampling intervals (e.g. 15 to $30 \mathrm{~min}$ ) to better resolve the temporal evolution of the isotope ratio of the cloud droplets. Furthermore, to investigate the cloud's inhomogeneity, simultaneous measurements at different heights within in the cloud and the development of airborne collection techniques of cloud water for isotope analysis would be needed.

Acknowledgements. We would like to thank Annika Ackermann for measuring the $\delta$ values of the cloud water samples and performing the quality control of the measured isotope ratios. Any use of trade, firm, or product names is for descriptive purposes only and does not imply endorsement by the US Government.

Edited by: M. C. Facchini

\section{References}

Arends, B. G., Kos, G. P. A., Maser, R., Schell, D., Wobrock, W., Winkler, P., Ogren, J. A., Noone, K. J., Hallberg, A., Svenningsson, I. B., Wiedensohler, A., Hansson, H. C., Berner, A., Solly, I., and Kruisz, C.: Microphysics of clouds at Kleiner Feldberg, J. Atmos. Chem., 19, 59-85, doi:10.1007/BF00696583, 1994.

Bolin, B.: On the use of tritium as a tracer for water in nature, in: Proc. Sec. Intern. Conf. Peaceful Uses of Atomic Energy, 18, 336-344, International Meteorological Inst., Stockholm, Geneva, 1958.

Booker, D.: Exchange between water droplets and tritiated water vapour, Q. J. Roy. Meteor. Soc., 91, 73-79, 1964.

Cappa, C. D., Hendricks, M. B., DePaolo, D. J., and Cohen, R. C.: Isotopic fractionation of water during evaporation, J. Geophys. Res., 108, 4525, doi:10.1029/2003JD003597, 2003.

Collett, Jr., J., Herckes, P., Youngster, S., and Lee, T.: Processing of atmospheric organic matter by California radiation fogs, Atmos. Res., 87, 232-241, doi:10.1016/j.atmosres.2007.11.005, 2008.

Coplen, T. B.: Normalization of oxygen and hydrogen isotope data, Chem. Geol., 72, 293-297, doi:10.1016/0168-9622(88)90042-5, 1988.

Coplen, T. B.: Guidelines and recommended terms for expression of stable-isotope-ratio and gas-ratio measurement results, Rapid Commun. Mass Spectrom., 25, 2538-2560, doi:10.1002/rcm.5129, 2011.

Criss, R. E.: Principles of Stable Isotope Distribution, Oxford University Press, Oxford, p. 254, 1999.

Dansgaard, W.: Stable isotopes in precipitation, Tellus, 16, 436468, 1964.

Dansgaard, W., Johnsen, S., Clausen, H., Dahl-Jensen, D., Gundestrup, N., Hammer, C., Hvidberg, C., Steffensen, J., Sveinbjörnsdottir, A., Jouzel, J., and Bond, G.: Evidence for gen- eral instability of past climate from a $250-\mathrm{kyr}$ ice-core record, Nature, 364, 218-220, 1993.

Demoz, B., Collett Jr., J. L., and Daube Jr., B.: On the Caltech active strand cloudwater collectors, Atmos. Res., 41, 47-62, doi:10.1016/0169-8095(95)00044-5, 1996.

Farquhar, G. D., Cernusak, L. A., and Barnes, B.: Heavy water fractionation during transpiration., Plant Physiol., 143, 11-8, doi:10.1104/pp.106.093278, 2007.

Friedman, I., Machta, L., and Soller, R.: Water-vapor exchange between a water droplet and its environment, J. Geophys. Res., 57, 2761-2766, 1962.

Gedzelman, S. and Arnold, R.: Modeling the isotopic composition of precipitation, J. Geophys. Res., 99, 10455-10471, 1994.

Gehre, M., Geilmann, H., Richter, J., Werner, R., and Brand, W.: Continuous flow ${ }^{2} \mathrm{H} /{ }^{1} \mathrm{H}$ and and ${ }^{18} \mathrm{O} /{ }^{16} \mathrm{O}$ analysis of water samples with dual inlet precision, Rapid Commun. Mass Spectrom., 18, 2650-2660, 2004.

Gerber, H.: Direct measurement of suspended particulate volume concentration and far-infrared extinction coefficient with a laserdiffraction instrument, Appl. Opt., 30, 4824-4831, 1991.

Hall, W. and Pruppacher, H.: The survival of ice particles falling from cirrus clouds in subsaturated air, J. Atmos. Sci., 33, 19952006, 1976.

Holm, S.: A simple sequentially rejective multiple test procedure, Scand. J. Stat., 6, 65-70, 1979.

Jouzel, J.: Isotopes in Clouds Physics: Multiphase and Multistage Condensation Processes, in: Handbook of Environmental Isotope Geochemistry, Volume 2, The Terrestrial Environment, B, edited by: Fritz, P. and Fontes, J., chap. 2, pp. 61-112, Elsevier Science Publischer B.V., Amsterdam, The Netherlands, 1986.

Jouzel, J., Merlivat, L., and Roth, E.: Isotopic study of hail, J. Geophys. Res., 80, 5015-5030, doi:10.1029/JC080i036p05015, 1975.

Kaul, D. S., Gupta, T., Tripathi, S. N., Tare, V., and Collett, J. L.: Secondary organic aerosol: a comparison between foggy and nonfoggy days., Environ. Sci. Technol., 45, 7307-7313, doi:10.1021/es201081d, 2011.

Kinzer, G. D. and Gunn, R.: The evaporation, temperature and thermal relaxation-time of freely falling waterdrops, J. Meteorol., 8, 71-83, 1951.

Lee, J.-E. and Fung, I.: Amount effect of water isotopes and quantitative analysis of post-condensation processes, Hydrol. Process., 22, 1-8, doi:10.1002/hyp.6637, 2007.

Legendre, P. and Legendre, L.: Numerical Ecology, 20, Elsevier Science, p. 853, 1998.

Michna, P., Schenk, J., Wanner, H., and Eugster, W.: MiniCASCC - A battery driven fog collector for ecological applications, in: Proceedings of the Fourth International Conference on Fog, Fog Collection and Dew, La Serena, Chile, 22-27 July 2007, 169$172,2007$.

Moore, K. F., Sherman, D. E., Reilly, J. E., and Collett Jr., J. L.: Drop size-dependent chemical composition in clouds and fogs. Part I. Observations, Atmos. Environ., 38, 1389-1402, doi:10.1016/j.atmosenv.2003.12.013, 2004a.

Moore, K. F., Sherman, D. E., Reilly, J. E., Hannigan, M. P., Lee, T., and Collett Jr., J. L.: Drop size-dependent chemical composition of clouds and fogs. Part II: Relevance to interpreting the aerosol/trace gas/fog system, Atmos. Environ., 38, 1403-1415, doi:10.1016/j.atmosenv.2003.12.014, 2004b. 
Petit, J. R., Jouzel, J., Raynaud, D., Barkov, N. I., Barnola, J. M., Basile, I., Bender, M., Chappellaz, J., Davis, M., Delaygue, G., Delmotte, M., Kotlyakov, V. M., Legrand, M., Lipenkov, V. Y., Lorius, C., Pepin, L., Ritz, C., Saltzman, E., and Stievenard, M.: Climate and atmospheric history of the past 420,000 years from the Vostok ice core, Antarctica, Nature, 399, 429-436, 1999.

Pruppacher, H. R. and Klett, J. D.: Microphysics of Clouds and Precipitation, Kluwer Academic Publishers, Dordrecht, The Netherlands, p. 955, 1997.

Raja, S., Raghunathan, R., Yu, X.-Y., Lee, T., Chen, J., Kommalapati, R. R., Murugesan, K., Shen, X., Qingzhong, Y., Valsaraj, K. T., and Collett, J. L.: Fog chemistry in the Texas Louisiana Gulf Coast corridor, Atmos. Environ., 42, 2048-2061, doi:10.1016/j.atmosenv.2007.12.004, 2008.

Risi, C., Bony, S., Vimeux, F., Descroix, L., Ibrahim, B., Lebreton, E., Mamadou, I., and Sultan, B.: What controls the isotopic composition of the African monsoon precipitation? Insights from event-based precipitation collected during the 2006 AMMA field campaign, Geophys. Res. Lett., 35, L24808, doi:10.1029/2008GL035920, 2008.

Schmid, S., Burkard, R., Frumau, K., Tobon, C., Bruijnzeel, L., Siegwolf, R., and Eugster, W.: Using eddy covariance and stable isotope mass balance techniques to estimate fog water contributions to a Costa Rican cloud forest during the dry season, Hydrol. Process., 25, 429-437, doi:10.1002/hyp.7739, 2010.
Scholl, M., Eugster, W., and Burkard, R.: Understanding the role of fog in forest hydrology: stable isotopes as tools for determining input and partitioning of cloud water in montane forests, Hydrol. Process., 25, 353-366, doi:10.1002/hyp.7762, 2011.

Seinfeld, J. H. and Pandis, S. N.: Atmospheric Chemistry and Physics: From Air Polution to Climate Change, John Wiley and Sons, New Jersey, USA, 2006.

Spiegel, J. K., Aemisegger, F., Scholl, M., Wienhold, F. G., J. L. Collett Jr., Lee, T., van Pinxteren, D., Mertes, S., Tilgner, A., Herrmann, H., Werner, R. A., Buchmann, N., and Eugster, W.: Temporal evolution of stable water isotopologues in cloud droplets during HCCT-2010, Atmos. Chem. Phys. Discuss., 12, 1513915175, doi:10.5194/acpd-12-15139-2012, 2012.

Stewart, M.: Stable isotope fractionation due to evaporation and isotopic exchange of falling water drops: application to atmospheric processes and evaporation of lakes, J. Geophys. Res., 80, 11331146, 1975.

Yakir, D. and Sternberg, L. d. S. L.: The use of stable isotopes to study ecosystem gas exchange, Oecologia, 123, 297-311, doi:10.1007/s004420051016, 2000. 